\title{
Neuronal Regulation of Glutamate Transporter Subtype Expression in Astrocytes
}

\author{
Raymond A. Swanson, ${ }^{1}$ Jialing Liu, ${ }^{1}$ Johann W. Miller, ${ }^{1}$ Jeffrey D. Rothstein, ${ }^{2}$ Kevin Farrell, ${ }^{1}$ Becky A. Stein, ${ }^{1}$ \\ and Maria C. Longuemare ${ }^{1}$ \\ ${ }^{1}$ Department of Neurology, University of California, San Francisco and Veterans Affairs Medical Center, San Francisco, \\ California 94121, and 2Deparment of Neuroscience, The Johns Hopkins Medical Center, Baltimore, Maryland 21287
}

\begin{abstract}
GLT-1, GLAST, and EAAC1 are high-affinity, $\mathrm{Na}^{+}$-dependent glutamate transporters identified in rat forebrain. The expression of these transporter subtypes was characterized in three preparations: undifferentiated rat cortical astrocyte cultures, astrocytes cocultured with cortical neurons, and astrocyte cultures differentiated with dibutyryl cyclic AMP (dBcAMP). The undifferentiated astrocyte monocultures expressed only the GLAST subtype. Astrocytes cocultured with neurons developed a stellate morphology and expressed both GLAST and GLT-1; neurons expressed only the EAAC1 transporter, and rare microglia in these cultures expressed GLT-1. Treatment of astrocyte cultures with $\mathrm{dBcAMP}$ induced expression of GLT-1 and increased expression of GLAST. These effects of dBcAMP on transporter expression were qualitatively similar to those resulting from coculture with neurons, but immunocytochemistry showed the pattern of transporter expression to be more complex in the coculture preparations. Compared with astro-
\end{abstract}

cytes expressing only GLAST, the dBcAMP-treated cultures expressing both GLAST and GLT-1 showed an increase in glutamate uptake $V_{\max }$, but no change in the glutamate $K_{\mathrm{m}}$ and no increased sensitivity to inhibition by dihydrokainate. Pyrrolidine-2,4-dicarboxylic acid and threo- $\beta$-hydroxyaspartic acid caused relatively less inhibition of transport in cultures expressing both GLAST and GLT-1, suggesting a weaker effect at GLT-1 than at GLAST. These studies show that astrocyte expression of glutamate transporter subtypes is influenced by neurons, and that $\mathrm{dBcAMP}$ can partially mimic this influence. Manipulation of transporter expression in astrocyte cultures may permit identification of factors regulating the expression and function of GLAST and GLT-1 in their native cell type.

Key words: dibutyryl CAMP; dihydrokainate; GLT-1; threo- $\beta$ hydroxyaspartate; glutamate uptake; PDC; pyrrolidine-2,4-dicarboxylate; microglia; GLAST
Glutamate is the major excitatory neurotransmitter of the mammalian central nervous system (Fonnum, 1984). Extracellular glutamate is normally kept at low levels by $\mathrm{Na}^{+}$-dependent transport into glia and neurons (Hertz, 1979; Nichols and Attwell, 1990). Three $\mathrm{Na}^{+}$-dependent transporter subtypes have been identified in rat forebrain: GLAST (Storck et al., 1992; Tanaka, 1993), GLT-1 (Pines et al., 1992), and EAAC1 (Kanai and Hediger, 1992). EAAC1 is expressed only in neurons, whereas GLAST and GLT-1 are expressed primarily in glia (Kanai and Hediger, 1992; Storck et al., 1992; Rothstein et al., 1994; Chaudhry et al., 1995; Lehre et al., 1995; Schmitt et al., 1996; Furuta et al., 1996). Three similar transporters have been cloned from human brain, and the provisional human homologs have been termed EAAT1 (GLAST), EAAT2 (GLT-1), and EAAT3 (EAAC) (Arriza et al., 1994). A fourth subtype, EAAT4, has been identified in human cerebellum (Fairman, 1995). The transporters differ in kinetic properties (Arriza et al., 1994; Fairman et al., 1995; Zerangue et al., 1995; Dowd et al., 1996) and distribution in brain (Rothstein et al., 1994, 1995; Chaudhry et al. 1995; Lehre et al., 1995; Schmitt et al., 1996; Sutherland et al., 1996).

Received July 11, 1996; revised Oct. 30, 1996; accepted Nov. 7, 1996.

This work was supported by National Institutes of Health Grant RO1 NS31914-03, the Veterans Administration Merit Review program (R.A.S.), the Muscular Dystrophy Association, and the Cal Ripkin/Lou Gehrig Neuromuscular Research Fund (J.D.R.). We thank Dr. Stephen M. Massa for assistance with the immunoblot analyses.

Correspondence should be addressed to Dr. Raymond A. Swanson, (127) Neurology, VAMC, 4150 Clement Street, San Francisco, CA 94121.

Copyright (C) 1997 Society for Neuroscience 0270-6474/97/170932-09\$05.00/0
Astrocytes, rather than neurons, perform the majority of glutamate uptake in brain (McLennan, 1976; Rothstein, 1996). Downregulation of the astrocyte transporters GLAST and GLT-1 by chronic infusion of antisense mRNA causes elevated extracellular glutamate levels and neuronal death (Rothstein, 1996). GLAST and GLT-1 are expressed throughout the central nervous system, but regional, cellular, and subcellular differences are observed (Rothstein et al., 1994; Chaudhry et al. 1995; Lehre et al., 1995; Schmitt et al., 1996; Sutherland et al., 1996). Expression patterns also vary during development, with GLAST expression predominating at early stages and progressively more GLT-1 expression observed with maturity (Furuta et al., 1996; Sutherland et al., 1996). Glutamatergic deafferentation reduces both GLAST and GLT-1 expression (Levy et al., 1995), and neuronal degeneration characteristic of amyotrophic lateral sclerosis is associated with a selective reduction in GLT-1 expression (Rothstein et al., 1995). Together, these observations suggest that neuronal influences may be important in determining the expression pattern of the astrocyte transporter subtypes.

The primary cortical culture system provides a means of assessing these influences. Astrocytes may be cultured alone or in coculture with neurons. Astrocytes cocultured with neurons change from a polygonal to a process-bearing morphology that is more characteristic of astrocytes in situ. Process bearing may also be induced by treatment with dibutyryl cAMP (dBcAMP). This agent acts at cAMP-responsive sites and is widely used to mimic neuronal influences on astrocyte cultures (Sensenbrenner et al., 
1980; Juurlink and Hertz, 1985; Hertz 1990). The present study examines the expression of GLT-1, GLAST, and EAAC1 in three preparations: polygonal "undifferentiated" astrocyte cultures; astrocytes cocultured with cortical neurons; and astrocytes treated with $\mathrm{dBcAMP}$. Selective induction of GLT-1 by dBcAMP further allowed comparison of uptake kinetics in astrocytes expressing only GLAST with astrocytes expressing both GLAST and GLT-1. This work has appeared previously in abstract form (Stein et al., 1996).

\section{MATERIALS AND METHODS}

Primary cortical astrocyte cultures. Primary cortical astrocyte cultures were prepared by the method of Hertz (1985) with minor modifications. Forebrain cortices were dissected from 1-day-old Sprague Dawley rats and the meninges carefully removed. Dissociation was accomplished by incubation in papain/DNase, followed by trituration. The dissociated cells were washed, suspended in Eagle's MEM with 10\% FBS (Hyclone, Logan, UT) and glutamine (2 mM), and plated in Falcon 24 well tissue culture plates or Corning $75 \mathrm{~cm}^{2}$ flasks at an approximate density of $5 \times$ $10^{4}$ cells $/ \mathrm{cm}^{2}$. The cultures were maintained in a humidified, $5 \% \mathrm{CO}_{2}$ incubator at $37^{\circ} \mathrm{C}$. The medium was exchanged with fresh medium at day 5. At confluence (days 12-15), $10 \mu \mathrm{M}$ cytosine arabinoside was added to prevent proliferation of other cell types. This medium was removed after $48 \mathrm{hr}$ and replaced with medium containing 3\% FBS. Cultures treated with $\mathrm{dBcAMP}$ received $0.15 \mathrm{~mm}$ from freshly prepared stock solutions at this time and with each subsequent media change. The media were exchanged with fresh media weekly. Cultures were used at 25-40 d in vitro except where stated otherwise.

Astrocyte-neuronal cocultures. Forebrain cortices were dissected from fetal (embryonic day 16) Sprague Dawley rats and dissociated as above. The dissociated cells were washed and suspended in Eagle's MEM with $10 \%$ FBS (Hyclone) and glutamine (2 mM). The cells were plated at an approximate density of $1 \times 10^{6}$ cells $/ \mathrm{cm}^{2}$ onto confluent astrocyte cultures. The astrocyte cultures used were $14-20 \mathrm{~d}$ old and had not been treated with dBcAMP. Five days after plating of the embryonic cells, 10 $\mu \mathrm{M}$ cytosine arabinoside was added to prevent proliferation of nonneuronal cells. This media was replaced after $48 \mathrm{hr}$ with glial conditioned media (prepared by placing $10 \mathrm{ml}$ of MEM with $2 \mathrm{~mm}$ glutamine and 5\% FBS in a $75 \mathrm{~cm}^{2}$ flask of confluent cortical astrocytes for $24 \mathrm{hr}$ ). The medium was half-exchanged with fresh glial-conditioned media every $7 \mathrm{~d}$. These cultures were used 18-24 d after plating of the neuronal cell layer. The corresponding age of the preexisting glial layer was therefore 32-44 $\mathrm{d}$ in vitro.

Immunocytochemistry. Affinity-purified polyclonal antibodies to GLAST, GLT-1, and EAAC were prepared in rabbits as described previously and characterized (Rothstein et al., 1994, 1996). The GLAST antibody recognizes the $\mathrm{N}$ terminal, and the GLT-1 and EAAC antibodies recognizes the $\mathrm{C}$ terminal of the respective proteins. Immunoreactivity of both antibodies is abolished by preabsorbtion with synthetic antigen peptides (Rothstein et al., 1994). Mouse antibodies to neurofilament protein (NFP) and vimentin were obtained from Dako (Carpenteria, CA), mouse antibodies to the microglia epitope OX42 (Castellano et al., 1991) were obtained from Harlan (Indianapolis, IN), and mouse antibodies to the oligodendrocyte marker $2^{\prime}, 3^{\prime}$-cyclic-3'-phosphohydrolase (CNP; Cammer, 1990) were obtained from Promega (Madison, WI). Cultures were washed once with $10 \mathrm{~mm}$ PBS, $\mathrm{pH}$ 7.4, and fixed for $30 \mathrm{~min}$ with $4 \%$ paraformaldehyde in PBS. After three washes, primary antibodies were applied in PBS containing $0.2 \%$ Triton X-100 and 2\% horse serum (for mouse primary antibodies) or $2 \%$ goat serum (for rabbit primary antibodies) for $18 \mathrm{hr}$ at $4^{\circ} \mathrm{C}$. Excess primary antibody was removed with three additional washes, and the cultures were incubated with biotinylated horse anti-mouse or goat anti-rabbit secondary antibody (Vector Laboratories, Burlingame, CA) in PBS containing $0.2 \%$ Triton $\mathrm{X}-100$ and $2 \%$ serum for $2 \mathrm{hr}$ at room temperature. Staining was developed with diaminobenzidine using the avidin-conjugated peroxidase supplied in the form of Vector Laboratories ABC Standard Elite kit and intensified with nickel (Hoffman et al., 1990).

Immunoblots. Cultures were washed with PBS and lysed in ice-cold RIPA buffer containing protease inhibitors (Harlowe and Lane, 1988). Proteins were denatured by boiling for $5 \mathrm{~min}$ in $5 \%$ 2-mercaptoethanol. Stacking gels (5\% acrylamide) were loaded with $0.3-10 \mu \mathrm{g}$ protein along with Rainbow molecular weight markers (Amersham, Arlington Heights,
IL) and run for $30 \mathrm{~min}$ at $90 \mathrm{~W}$, then run through a $7.5 \%$ acrylamide gel for $90 \mathrm{~min}$ at $150 \mathrm{~W}$. Proteins were electrophoretically transferred $(75 \mathrm{~V}$ for $3.5 \mathrm{hr}$ ) to a polyvinylidene fluoride membrane (Millipore, Bedford, MA). The membranes were stored in a blocking/wash buffer composed of $0.1 \%$ Tween 20 and $1 \%$ nonfat dry milk in PBS for at least $3 \mathrm{hr}$. Membranes were washed with PBS and stained with antibodies to GLAST, GLT-1, and EAAC1 as described for the immunocytochemistry. Densitometry was performed with a UMAX scanner using the NIHImage program.

Northern blots. Northern blots were prepared from mRNA isolated from cultured astrocytes by oligo-dT selection using the Fastrack 2.0 kit (Invitrogen, Portland, OR). Twenty $75 \mathrm{~cm}^{2}$ flasks of astrocytes cultured with and without dBcAMP were pooled to provide $\sim 2 \mu \mathrm{g}$ mRNA for each treatment group. The mRNA samples and RNA size markers (BRL, Grand Island, NY) were electrophoresed on a $2.2 \mathrm{M}$ formaldehyde denaturing $1.2 \%$ agarose gel and blotted onto a Duralon UV membrane (Stratagene, San Diego, CA). The membrane was UV cross-linked in a UV Stratalinker 1800 (Stratagene). Antisense oligonucleotides were prepared for GLAST (5'-CAC ATC CTC CTT GGT GAT GTT CTG AAC TTT CTT CTT GGC CAG GAG CGT CCG CTT GCG CAC-3') and for GLT-1 (5'-CAG CAC AGC GGC AAT GAT GGT CGT GGA CAT GTA ATA TAC CAT GGC TCT CGT GCC TAG-3'; Oligos Etc., South Orange, NJ). The oligonucleotides were end labeled with $\left[{ }^{32} \mathrm{P}\right]$-dCTP with terminal 2-deoxytransferase (BRL) to achieve a specific activity of $4-8 \times 10^{8} \mathrm{cpm} / \mu \mathrm{g}$ DNA. The GLAST oligonucleotide was hybridized to the membrane for $20 \mathrm{hr}$ at $42^{\circ} \mathrm{C}$ in buffer containing $50 \%$ deionized formamide, $4 \times$ SSPE, $1 \%$ SDS, $2 \times$ Denhardt's solution, $10 \mu \mathrm{g}$ salmon sperm DNA, and $2 \times 10^{6} \mathrm{cpm} / \mathrm{ml}$ of probe (Sambrook et al., 1989). After hybridization, the membrane was washed with increasing stringency at $42-56^{\circ} \mathrm{C}$ and autoradiographs were prepared by exposure to Kodak Biomax MS film with intensifying screen at $-70^{\circ} \mathrm{C}$ for $30-60 \mathrm{~min}$. After stripping the membrane by immersion for $30 \mathrm{sec}$ in boiling $0.1 \%$ SDS, the membrane was hybridized with the GLT-1 probe and an autoradiograph prepared by the same procedure. Last, the membrane was again stripped and hybridized to a labeled cyclophilin probe to produce a third autoradiograph. Densitometry was performed with a UMAX scanner using the NIH-Image program.

Glutamate uptake. Glutamate uptake was measured as described previously (Swanson et al., 1995). The culture media were replaced with fresh media on the evening before the uptake studies. Assays were begun by replacing the culture media with a modified HBSS containing $2 \mathrm{~mm}$ glucose buffered to $\mathrm{pH} 7.2$ with $5 \mathrm{~mm}$ PIPES. After a $30 \mathrm{~min}$ preincubation in this media, each culture well received $0.01 \mu \mathrm{Ci} / \mathrm{ml} \mathrm{L}-[\mathrm{U}]-{ }^{14} \mathrm{C}$ glutamate (American Radiochemicals, St. Louis, MO) plus unlabeled glutamate to achieve final glutamate concentrations of 2-250 $\mu \mathrm{M}$. Studies using uptake inhibitors were performed with $10 \mu \mathrm{M}$ glutamate and $1 \mathrm{~mm}$ inhibitor. Inhibitors were added from $15 \times$ iso-osmolar, $\mathrm{pH} 7.2$ stock solutions $3 \mathrm{~min}$ before the addition of glutamate. Arachidonic acid stock was prepared immediately before use from a freshly opened container. In all studies, uptake was terminated after $7 \mathrm{~min}$ incubation at $37^{\circ} \mathrm{C}$ by two washes in ice-cold HBSS, followed immediately by cell lysis in $0.5 \mathrm{~N}$ $\mathrm{NaOH} / 0.05 \%$ lauryl sulfate. Aliquots were taken for scintillation counting and for protein assays (Lowry et al., 1951) using BSA standards. Previous studies have shown uptake to be linear with time through at least $10 \mathrm{~min}$. Blanks prepared with osmotically lysed cells showed that $<0.4 \%$ of the ${ }^{14} \mathrm{C}$ accumulation resulted from glutamate binding.

Statistical comparisons were performed with Student's two-tailed $t$ test or with ANOVA and the Bonferroni correction for multiple comparisons. All results are expressed as mean $\pm \mathrm{SD}$.

\section{RESULTS}

Primary astrocyte cultures grown in the absence of neurons maintain a polygonal morphology and are considered undifferentiated (Sensenbrenner et al., 1980; Juurlink and Hertz, 1985; Hertz 1990). Addition of dBcAMP to the media induces process extension and increases expression of glial fibrillary acidic protein (GFAP). As shown in Figure 1, astrocytes cultured without dBcAMP express only the GLAST transporter. The intensity of GLAST immunoreactivity varied from cell to cell, but no cells appeared unstained. Rare cells (less than one per five photographic fields) stained for GLT-1 (Fig. 1B). These cells had 

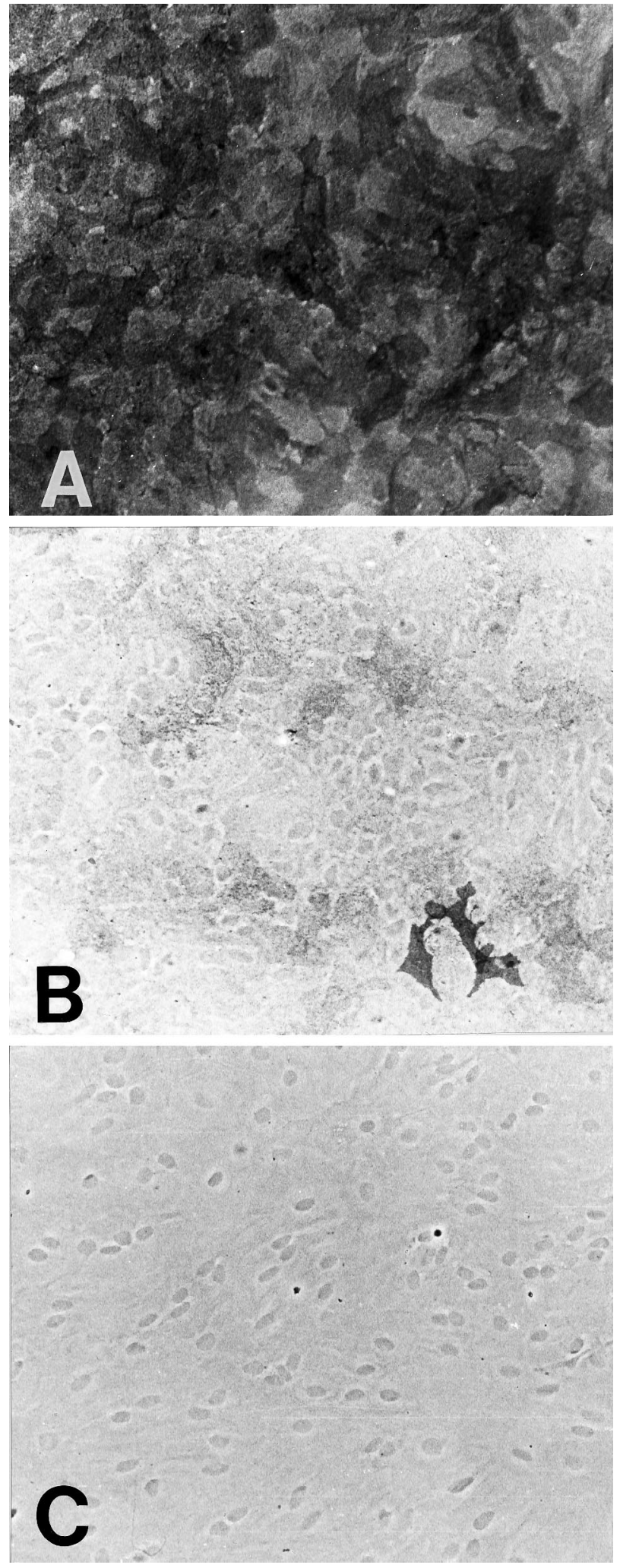

Figure 1. GLAST and GLT-1 expression in undifferentiated astrocyte cultures (not treated with dBcAMP). GLAST is expressed throughout the cultures $(A)$, but GLT-1 is not $(B)$. The two cells staining for GLT in $B$ have a morphology atypical for astrocytes. No staining was observed in the absence of primary antibody $(C)$; nuclei appear dark because of the phase-contrast optics.
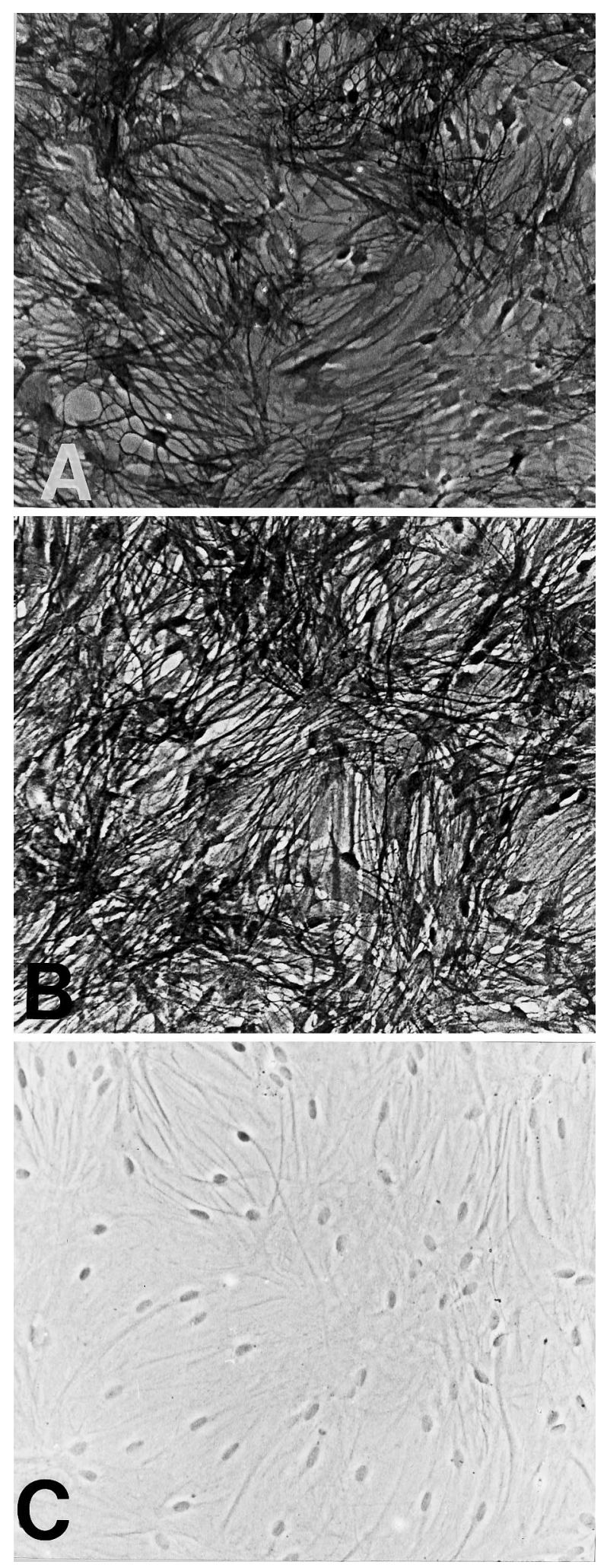

Figure 2. GLAST and GLT-1 expression in process-bearing astrocyte cultures (treated with dBcAMP). Both GLAST $(A)$ and GLT-1 $(B)$ are expressed in cell bodies and processes throughout cultures. No staining was observed in the absence of primary antibody $(C)$. 

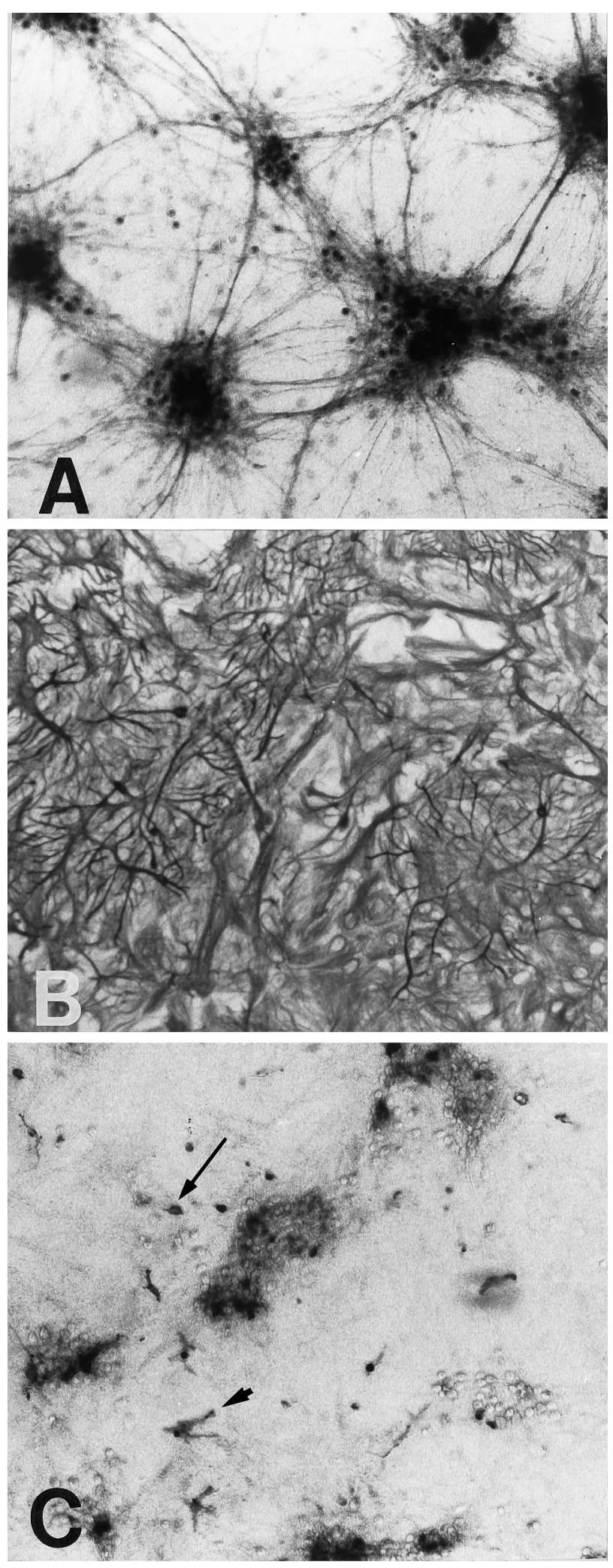

Figure 3. Immunostaining of neurons, astrocytes, and microglia in astrocyte-neuronal cocultures. Antibody to neurofilament protein $(A)$ shows neurons arranged in loose clusters. The astrocyte layer is stained with glia fibrillary acidic protein $(B)$ and shows cells with both polygonal and stellate shapes. Staining with OX42 $(C)$ shows scattered microglia among and between the neuronal clusters. These cells exhibit both branched (arrowhead) and spherical (arrow) morphologies.
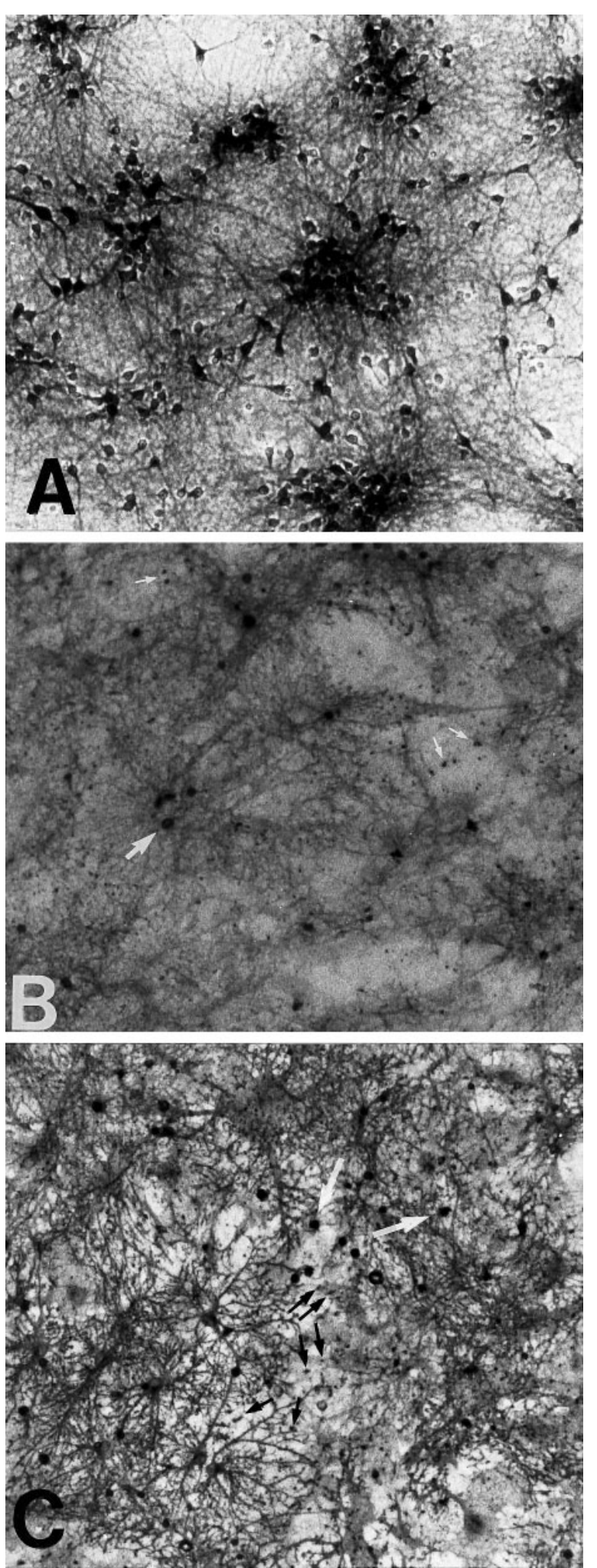

Figure 4. EAAC1, GLAST, and GLT-1 expression in cortical cultures containing glia and neurons. EAAC1 expression $(A)$ was restricted to neuronal cell bodies and processes. GLAST $(B)$ was expressed diffusely in the astrocyte layer. More focal and intense expression was observed in some cell bodies (large arrow) and in a scattered, punctate manner among the processes (small arrows). GLT-1 was strongly expressed by some, but not all, of the astrocytes $(C)$. These cells exhibited a highly branched, stellate morphology. Foci of intense staining were observed in the same pattern as with GLAST: small cell bodies (white arrows) and scattered among the processes (small black arrows). 
morphology atypical for astrocytes and may represent contaminating microglia. EAAC1 staining was seen only in rare neurons present at the edges of some wells (not shown). The apparent faint staining of cell nuclei in Figure $1, B$ and $C$, is an artifact of the phase-contrast optics used to visualize the astrocyte morphology.

Cultures treated with $\mathrm{dBcAMP}$ consist of elongated, processbearing cells that bind both the GLAST and GLT-1 antibodies (Fig. 2). There is again cell-to-cell variability in staining intensity, and open spaces observed in the GLT-1 -stained cultures suggest that some astrocytes may remain GLT-1 negative even after treatment with dBcAMP.

Astrocytes in coculture with neurons display more complex morphologies and glutamate transporter expression patterns. Staining with GFAP showed the astrocytes to have a stellate, highly branched morphology as well as more polygonal shapes (Fig. $3 B$ ). Staining with antibody to vimentin gave a nearly identical pattern (not shown). Neurons, as identified with NFP, have large perikarya, few processes, and form loose clusters on the astrocyte layer (Fig. $3 A$ ). These cultures also contain scattered microglia, as identified by presence of the OX42 epitope (Castellano et al., 1991). Microglia can assume a variety of shapes in culture (Castellano et al., 1991; Suzumura et al., 1991), and, as shown in Figure $3 C$, microglia present in the astrocyte-neuronal cocultures assumed an irregular branching pattern when located between clusters of neurons, and a more spherical "amoeboid" pattern when present within the neuronal clusters. Staining for the oligodendrocyte marker CNP (Cammer, 1990) revealed a very sparse distribution of this cell type; fewer than one cell per two culture wells.

Immunostaining of the astrocyte-neuronal cocultures with the EAAC1 antibody showed this transporter to be restricted to neuronal perikarya and, to a lesser extent, neuronal processes (Fig. 4C). GLAST was expressed throughout the astrocyte layer and was not expressed by neurons (Fig. $4 A$ ). GLT-1 staining showed a similar pattern to GLAST, but was more intense over the highly stellated astrocytes (Fig. $4 B$ ). With both GLAST and GLT-1, intense staining was also seen in cell bodies scattered among the neuronal clusters. These cells appear too small to be neurons and may represent a subset of the astrocytes, microglia, or another cell type. Small, punctate foci of staining were also scattered between the neuronal clusters, and these may identify synapses (Rothstein et al., 1994; Chaudhry et al., 1995; Lehre et al., 1995). It is not possible to rule out a neuronal localization of these small foci, but this is unlikely because GLT-1 and GLAST appear colocalized at these foci, and GLAST mRNA has not been identified in neurons. The extremely low density of oligodendrocytes in these cultures excludes localization of transporter immunoreactivity to that cell type.

Transporter expression was quantified with immunoblots prepared with serial dilutions of proteins from the three culture preparations (Fig. 5). The GLAST antibody recognized a protein in all three culture types with a molecular weight of $\sim 65 \mathrm{kDa}$. The GLT-1 antibody recognized a band at $\sim 70 \mathrm{kDa}$ only in astrocytes cocultured with neurons or treated with dBcAMP. Both the GLAST and GLT-1 antibodies also produced faint bands at higher molecular weights corresponding to protein aggregates. Lanes stained with the EAAC1 antibody revealed a single band at $\sim 70 \mathrm{kDa}$ in the astrocyte neuronal coculture and no staining in either of the two astrocyte preparations without neurons (not shown). Densitometry showed GLAST expression to be increased

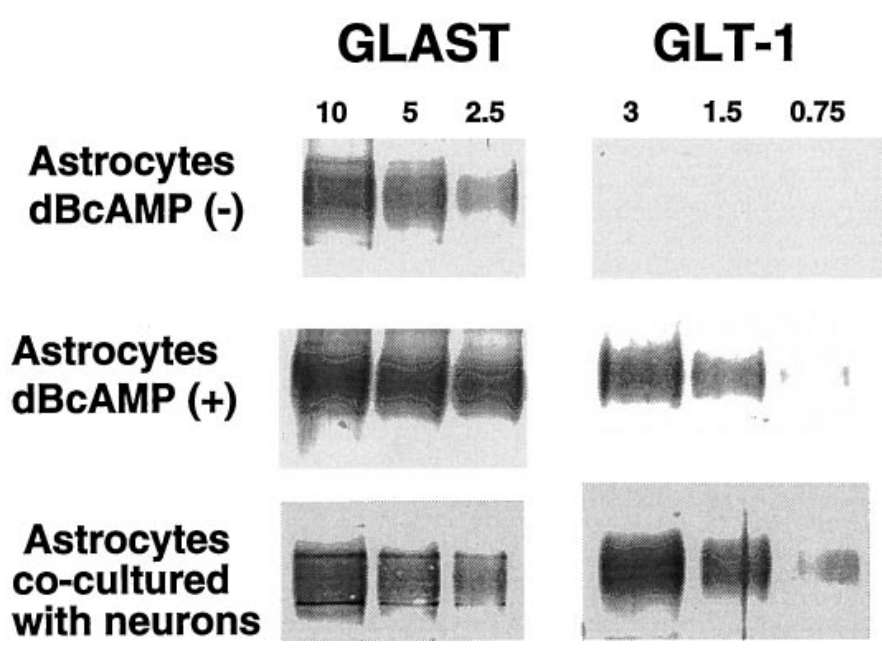

Figure 5. Western blots confirm that astrocyte GLT-1 expression is induced and GLAST expression is increased both by incubation with dBcAMP $(0.15 \mathrm{~mm})$ and by coculture with neurons. Numbers above the lanes denote $\mu \mathrm{g}$ protein loaded onto the lanes.

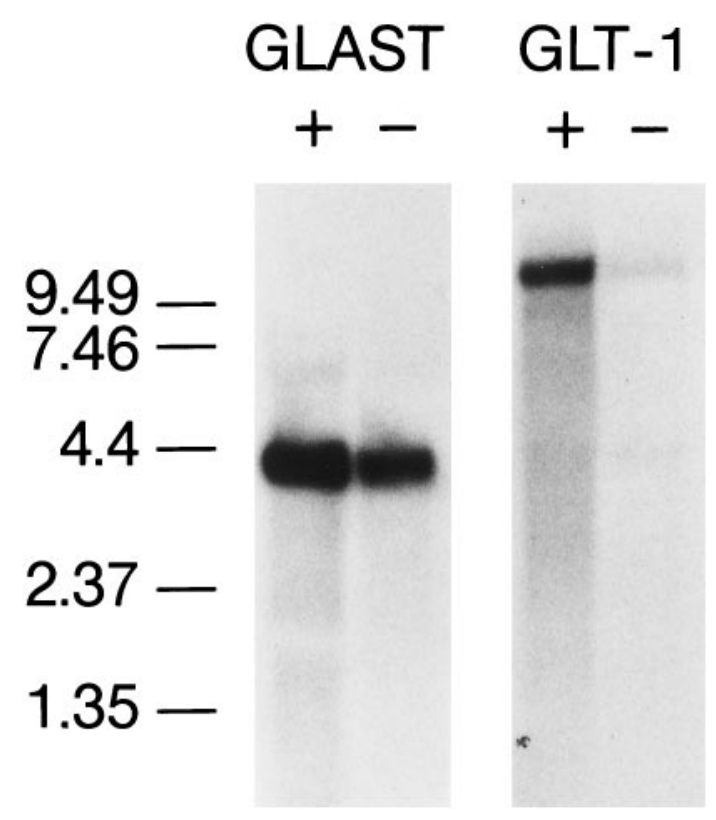

Figure 6. Northern blots show that GLAST and GLT-1 mRNA levels are both increased in astrocyte cultures treated with dBcAMP $(+)$. Nontreated cultures $(-)$ produced only a faint GLT-1 signal and expressed less GLAST mRNA than did the dBcAMP-treated cultures. The cyclophilin bands (not shown) had relative optical densities of 320 in the dBcAMP $(+)$ cultures and 346 in the dBcAMP $(-)$ cultures, confirming near equal loading of mRNA.

approximately threefold by $\mathrm{dBcAMP}$ and 2-fold by coculture with neurons. GLT-1 expression was not detected in astrocytes not treated with dBcAMP, but expression was markedly induced by coculture with neurons and, to a lesser extent, by treatment with dBcAMP. Astrocyte expression of GLAST and GLT- 1 in the astrocyte-neuronal cocultures is underestimated by this method because a portion of the protein loaded onto these lanes is derived from neurons.

The expression of GLAST and GLT-1 mRNA (Fig. 6) showed 


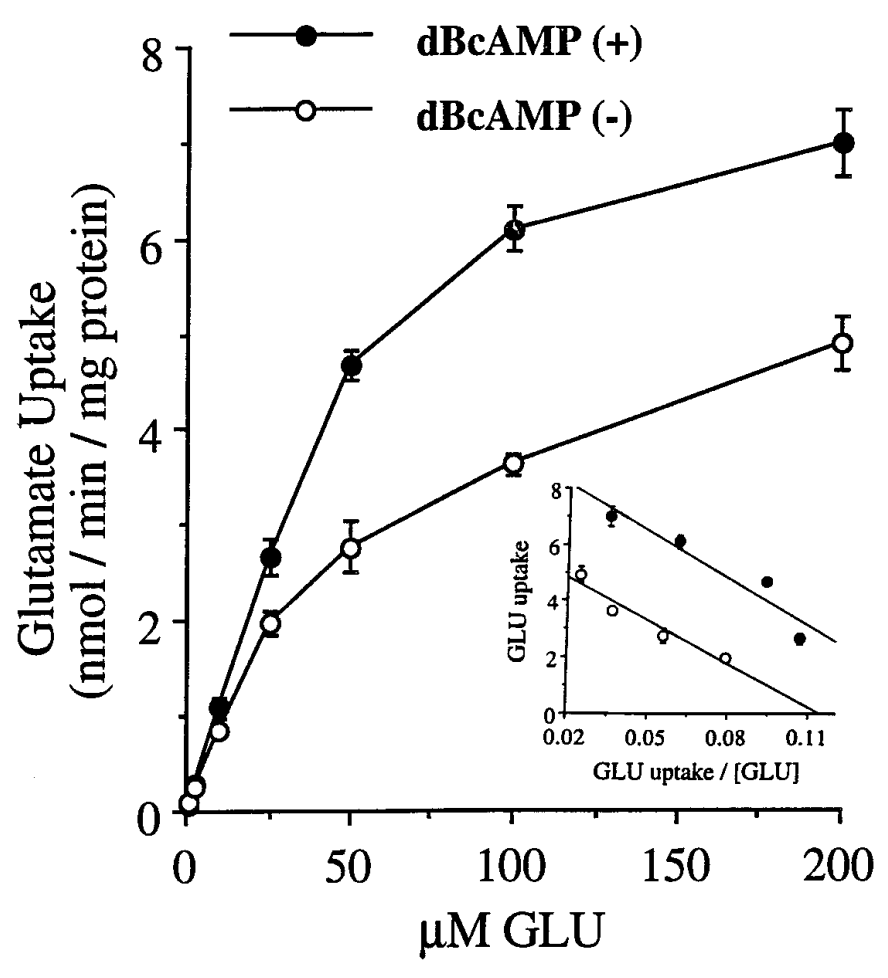

Figure 7. Glutamate $(G L U)$ uptake in astrocyte cultures with and without treatment with dBcAMP. $V_{\max }$ for glutamate uptake is significantly greater in cultures treated with $\mathrm{dBcAMP}$, whereas $K_{\mathrm{m}}$ is nearly identical. Inset shows Eadie Hofstee plot of the data. With dBcAMP: $V_{\max }=9.42$ $\mathrm{nmol} / \mathrm{min} / \mathrm{mg}$ protein; $K_{\mathrm{m}}=56 \mu \mathrm{M} ; r^{2}=0.90$. Without dBcAMP: $V_{\max }=$ $5.81 \mathrm{nmol} / \mathrm{min} / \mathrm{mg}$ protein; $K_{\mathrm{m}}=51 \mu \mathrm{M} ; r^{2}=0.93 ; n=8$.

a pattern similar to that of the transporter protein expression. Both the GLAST and GLT-1 antisense oligonucleotides hybridized to single bands at positions corresponding to the respective known mRNA sizes (Pines et al., 1992; Storck et al., 1992). GLAST mRNA was $\sim 50 \%$ more abundant in the dBcAMPtreated cultures than in nontreated cultures. GLT-1 mRNA was robustly induced in $\mathrm{dBcAMP}$-treated cultures but only faintly visualized in the nontreated cultures.

Glutamate uptake was studied in dBcAMP-treated astrocytes, expressing both GLT-1 and GLAST, and in astrocyte cultures not treated with $\mathrm{dBcAMP}$, which expressed only the GLAST transporter. As shown in Figure 7, treatment with dBcAMP caused an increase in uptake $V_{\max }$ but had no measurable effect on the apparent glutamate $K_{\mathrm{m}}$. Treating the cultures with dBcAMP for $45 \mathrm{~min}$, a period too short to permit changes in transporter expression, had no effect on the uptake kinetics (data not shown). The relative efficacy of several glutamate transport inhibitors in the two culture preparations is shown in Figure 8. Under the control conditions of no inhibitor and $10 \mu \mathrm{M}$ glutamate, the rate of glutamate uptake was $0.923 \pm$ $0.15 \mathrm{nmol} / \mathrm{min} / \mathrm{mg}$ protein in the untreated cells expressing only GLAST, and $1.15 \pm 0.024 \mathrm{nmol} / \mathrm{min} / \mathrm{mg}$ protein in the dBcAMP-treated cultures expressing both GLAST and GLT-1 ( $n=18$, pooled from three experiments). Uptake rates in the presence of the transport inhibitors $(1 \mathrm{~mm})$ were normalized to these control rates to assess the relative efficacy of each inhibitor on cultures expressing only GLAST or both GLAST and GLT-1 (Fig. 8). The competitive inhibitors pyrrolidine-2,4dicarboxylic acid (PDC) and threo- $\beta$-hydroxyaspartic acid

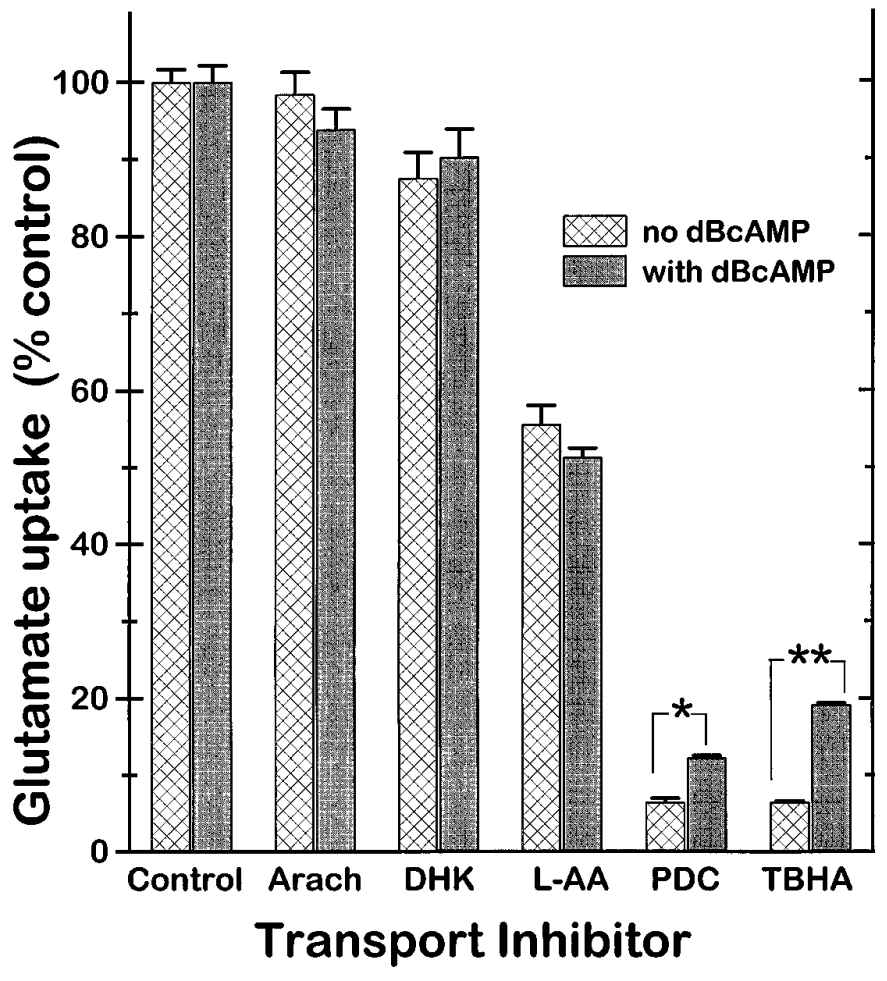

Figure 8. Effects of glutamate uptake inhibitors on astrocytes cultured with and without ABCAMP. PDC and TBHA exhibited significantly less inhibition on dBcAMP-treated cultures expressing both GLAST and GLT -1 than on nontreated cultures expressing only GLAST. Glutamate = $10 \mu \mathrm{M}$, inhibitors at $1 \mathrm{mM}$. Uptake is expressed as percent of the control (no inhibitor) uptake rate for the corresponding culture type. For cultures not treated with dBcAMP (expressing only GLAST), the control uptake rate was $0.923 \pm 0.15 \mathrm{nmol} / \mathrm{min} / \mathrm{mg}$ protein; for cultures treated with dBcAMP (expressing GLAST plus GLT-1), the control rate was $1.15 \pm$ $0.024 \mathrm{nmol} / \mathrm{min} / \mathrm{mg}$ protein. Arach, Arachidonic acid; ${ }^{*} p<0.001,{ }^{*} p<$ 0.05 by ANOVA with Bonferroni correction for multiple comparisons; $n=8-18$, pooled from three studies.

(TBHA) were significantly less effective in the cultures expressing GLT-1, suggesting that these compounds may have weaker effects at GLT- 1 than at GLAST. L- $\alpha$-aminoadipic acid (L-AA) also reduced uptake, but there was no significant difference between the two culture preparations. Dihydrokainate (DHK) and arachidonic acid (AA) did not significantly reduce glutamate uptake in either culture type.

Previous studies have shown DHK to be a potent inhibitor of GLT-1 in heterologous expression systems (Pines et al., 1992; Arriza et al., 1994). However, as shown in Figure 9, DHK had only negligible effects on the primary cultures prepared for these studies, including the dBcAMP-treated astrocyte cultures and the astrocyte-neuronal cocultures that express GLT-1 immunoreactivity and mRNA. Negligible inhibition was also seen when medium glutamate concentrations were reduced to $1 \mu \mathrm{M}$ or increased to $100 \mu \mathrm{M}$, or when $10 \mu \mathrm{M} \mathrm{MK}-801$ and $10 \mu \mathrm{M}$ DNQX were added to prevent possible effects of DHK or glutamate on glutamate receptors (results not shown).

\section{DISCUSSION}

These studies show that expression of $\mathrm{Na}^{+}$-dependent glutamate transporters in cortical astrocyte cultures is responsive to 


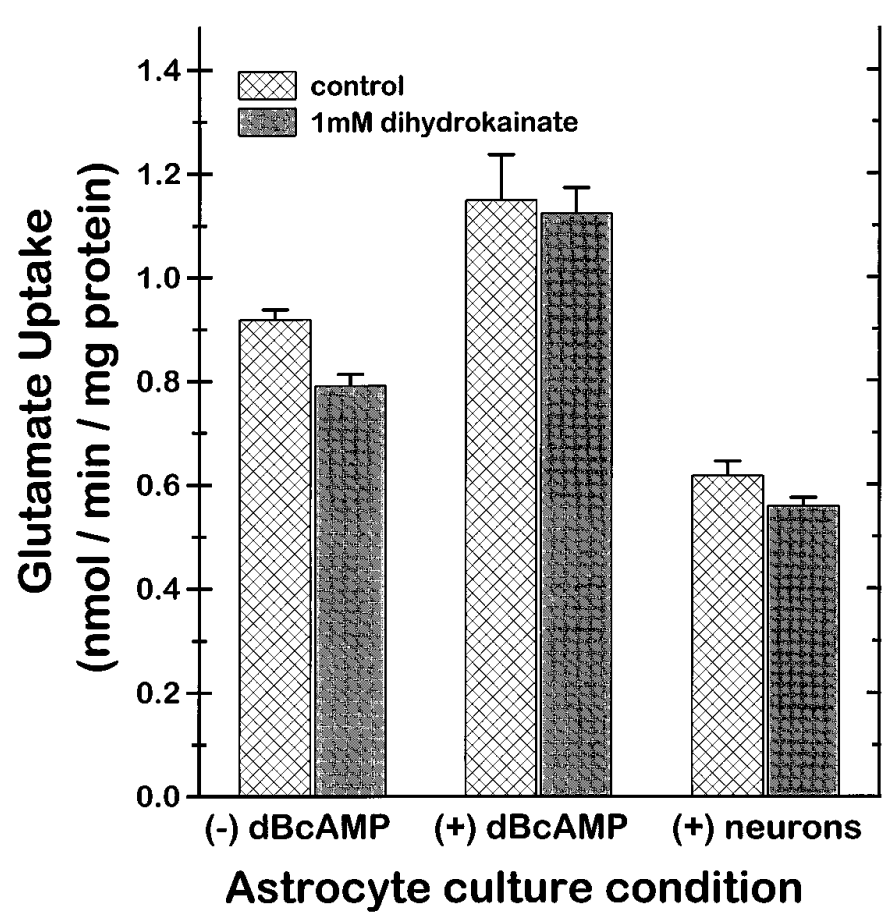

Figure 9. DHK had negligible effects on glutamate uptake in any of the three culture preparations studied. (-) $d B c A M P$, Without dBcAMP; (+) $d B c A M P$, cultured with $0.15 \mathrm{mM} \mathrm{dBcAMP}$ for $10 \mathrm{~d} ;(+)$ neurons, cultured with a neuronal layer plated onto the astrocytes for $10 \mathrm{~d}(n=10$, pooled from replicate studies). Values are normalized to total protein content of the culture wells, such that the apparently lower uptake rate in the astrocyte-neuronal cocultures compared with the astrocyte monocultures may reflect the contribution of neuronal protein to this denominator. $p>$ 0.05 for all pairwise comparisons between control and DHK conditions within each culture type.

neuronal influences. In the absence of neurons, astrocytes maintain polygonal shapes and express only the GLAST transporter. When cocultured with a neuronal layer, many of the astrocytes assume more complex morphologies, including stellate shapes similar to those of brain gray matter. Neuronal coculture also induces expression of GLT-1 and increases expression of GLAST. Immunostaining shows that neuronal coculture also induces a more complex distribution of both GLAST and GLT-1, with focal accumulations along astrocyte processes and some cell bodies.

Absence of GLT-1 expression is not simply a characteristic of immature or embryonic astrocytes because astrocytes in embryonic brain express both GLAST and GLT-1 mRNA (Furuta et al., 1996; Sutherland et al., 1996). Absence or downregulation of GLT-1 expression in situ is, however, associated with neuronal loss. Destruction of glutamatergic corticostriatal projections causes downregulation of GLT-1 as well as GLAST (Levy et al., 1995). A selective loss of GLT-1 is also seen in brain and spinal cord affected by amyotrophic lateral sclerosis (Rothstein, 1995; Bristol and Rothstein, 1996), although the cause of this striking loss is not yet known. The present findings support the general principle that normal expression of GLT-1 protein by astrocytes requires a neuronal signal. The nature of this neuronal signal remains to be determined, and it could be mediated by either secreted factors or direct contact between neurons and astrocytes.

$\mathrm{dBcAMP}$ is widely used to mimic neuronal influences on astro- cyte cultures (Sensenbrenner et al., 1980; Juurlink and Hertz, 1985; Hertz 1990). dBcAMP is cell permeant and causes activation of cAMP-responsive pathways. Neuronal stimulation of astrocyte $\beta$-adrenergic receptors is thought to activate these pathways in normal brain (Hertz, 1990). Cultures treated with dBcAMP exhibit a number of morphological and biochemical changes; however, these changes fall short of replicating astrocyte morphology in situ, and some authors have argued that cultures treated with dBcAMP are more similar to reactive astrocytes than to normal, gray matter astrocytes (Sensenbrenner et al., 1980). In the present study, astrocyte cultures treated with dBcAMP exhibited a marked change in morphology, changing from flat, polygonal cells to elongated, process-bearing cells. This morphology remains distinct from that of astrocytes cultured with neurons or present in normal brain. dBcAMP also induced a robust expression of GLT-1, although less than that induced by neuronal coculture. As with the morphological changes, dBcAMP seems to mimic, partially but imperfectly, the effects of neurons on glutamate transporter expression.

The fine structure of both GLT-1 and GLAST expression in the $\mathrm{dBcAMP}$-treated cultures differed from that observed in the neuronal cocultures. The complex pattern of small focal intensities in the astrocytes cocultured with neurons suggests that surface-surface interaction between the two cell types can influence GLT-1 expression. The punctate staining pattern may correspond to enrichment around synaptic complexes (Rothstein et al., 1994; Chaudhry et al., 1995; Lehre et al., 1995). Alternatively, this staining may be attributable to microglia located in and around the neuronal clusters (Fig. 3C) because microglia can express both GLT-1 and GLAST mRNA (Kondo et al., 1995). Neurons do not express GLT-1 protein in vivo (Rothstein et al., 1994, 1995, and unpublished observations), but small amounts of GLT-1 mRNA are detectable in neurons during development (Torp et al., 1994; Sutherland et al., 1996), and it is possible that some of the GLT-1 staining observed in the astrocyte-neuronal cultures is expressed by neurons. This possibility nonetheless seems unlikely because GLT-1 immunoreactivity does not stain any cells with a clearly neuronal morphology and because the distribution of GLT-1 staining is nearly identical to that of GLAST, which is not expressed by neurons.

Ruiz and Ortega (1995) reported GLAST RNA but not GLT-1 RNA in cultures of Bergmann glia. Kondo et al. (1995), using the reverse transcriptase PCR, also found abundant GLAST RNA but detected very low amounts of GLT-1 RNA from primary rat astrocyte cultures (prepared without dBcAMP). The present study confirms abundant GLAST mRNA and very little GLT-1 mRNA in the undifferentiated astrocyte preparation. Although no GLT-1 protein was detected in these cultures, the sensitivity of the Western blots and immunocytochemistry may have been insufficient to detect very low levels of expression. Treatment of astrocyte cultures with dBcAMP induced changes in GLAST and GLT-1 mRNA levels that were roughly parallel to the changes in transporter protein expression, suggesting effects at the transcriptional level.

Astrocyte cultures expressing only GLAST or GLAST plus GLT-1 allow assessment of the kinetic properties of these transporters in their native cell type. $V_{\max }$ was increased in the $\mathrm{dBcAMP}$-treated cultures, although the magnitude of increase was less than expected on the basis of the combined increase in GLAST and GLT-1 expression in these cells. $K_{\mathrm{m}}$ for glutamate uptake was virtually identical in the two preparations, suggest- 
ing either that GLT-1 has minimal contribution to net uptake velocity, or that the two transporters have very similar affinity for glutamate. Several previous studies using heterologous expression systems have shown kinetic differences between GLAST and GLT-1, or between their respective putative human homologs EAAT1 and EAAT2. Zerangue et al. (1995), using expression in frog oocytes and in HEK-293 cells, found that AA inhibited uptake by EAAT1 but stimulated uptake by EAAT2. Arriza et al. (1994), using transfected COS cells, found the uptake inhibitor DHK to have much larger effects on EAAT2 than EAAT1. Pines et al. (1992), using a proteoliposome preparation, likewise found DHK to be an effective inhibitor of GLT-1, whereas GLAST activity in Bergmann glia was not inhibited by DHK (Ruiz and Ortega, 1995). In view of these reports, the present findings are notable in that neither DHK nor AA had significant effects on glutamate uptake in cultures expressing either GLAST alone or GLAST plus GLT-1. This may in part reflect differences in species between the rat and human transporters. Alternatively, transporters expressed in astrocytes may be subject to kinetic regulation not present in the heterologous preparations. Kinetic regulation has been demonstrated previously in renal epithelial cells expressing the EAAC1 transporter (Nicholson and McGivan, 1996). It is possible that the glutamate transport observed in astrocytes expressing both GLAST and GLT-1 is predominately a result of GLAST activity under the assay conditions used. The present studies also found that the potent inhibitors PDC and TBHA had relatively less effect on cultures expressing both GLAST and GLT-1 than on cultures expressing GLAST alone. The marked overall reduction in glutamate uptake under these conditions may unmask uptake by GLT-1 that is less inhibited than uptake by GLAST.

Neither the functional differences between GLAST and GLT-1 nor the factors regulating their expression are well understood. The use of astrocyte and astrocyte-neuronal coculture preparations should permit further identification of kinetic and regulatory differences between the transporter subtypes and facilitate identification of regulatory influences.

\section{REFERENCES}

Arriza JL, Fairman WA, Wadiche JI, Murdoch GH, Kavanaugh MP, Amara SG (1994) Functional comparisons of three glutamate transporter subtypes cloned from human motor cortex. J Neurosci 14:5559-5569.

Bjørås M, Gjesdal O, Erickson JD, Torp R, Levy LM, Ottersen OP, Degree M, Storm-Mathisen J, Seeberg E, Danbolt NC (1996) Cloning and expression of a neuronal rat brain glutamate transporter. Mol Brain Res 36:163-168.

Bristol LA, Rothstein JD (1996) Glutamate transporter gene expression in amyotrophic lateral sclerosis motor cortex. Ann Neurol 39:676-679.

Cammer W (1990) Glutamine synthetase in the central nervous system is not confined to astrocytes. J Neuroimmunol 26:173-178.

Castellano B, Gonzalez B, Jensen MB, Pedersen EB, Finsen BR, Zimmer J (1991) A double staining technique for simultaneous demonstration of astrocytes and microglia in brain sections and astroglial cell cultures. J Histochem Cytochem 39:561-568.

Chaudhry FA, Lehre KP, Campagne MVL, Ottersen OP, Danbolt NC, Storm-Mathisen J (1995) Glutamate transporters in glial plasma membranes: highly differentiated localizations revealed by quantitative ultrastructural immunocytochemistry. Neuron 15:711-720.

Dowd LA, Coyle AJ, Rothstein JD, Pritchett DB, Robinson MB (1996) Comparison of $\mathrm{Na}^{+}$-dependent transport activity in synaptosomes, C6 glioma, and Xenopus oocytes expressing excitatory amino acid carrier 1 (EAAC1). Mol Pharmacol 49:465-473.

Fairman WA, Vandenberg RJ, Arriza JL, Kavanaugh MP, Amara SG
(1995) An excitatory amino acid transporter with properties of a ligandgated chloride channel. Nature 375:599-603.

Fonnum F (1984) Glutamate: a neurotransmitter in mammalian brain. J Neurochem 42:1-11.

Furuta A, Martin LJ, Rothstein JD (1996) Differential regulation of glutamate transporters in the developing rat brain. J Neurochem [Suppl. 1] $66: S 69$

Harlowe E, Lane D (1988) Antibodies: a laboratory manual. pp 447-677. Cold Spring Harbor, NY: Cold Spring Harbor Laboratory.

Hertz L (1979) Functional interactions between neurons and astrocytes. I. Turnover and metabolism of putative amino acid transmitters. Prog Neurobiol 13:277-323.

Hertz L (1990) Dibutyryl cyclic AMP treatment of astrocytes. I. Primary cultures as a substitute for normal morphogenic and "functiogenic" transmitter signals. In: Molecular aspects of development and aging of the nervous system (Lauder JM, Privat A, Giacobini E, Timiras P, Venadakis A, eds), pp 227-243. New York: Plenum.

Hertz L, Juurlink BHJ, Szuchet S (1985) Cell cultures. In: Handbook of neurochemistry, Vol 8, Ed 2 (Lajtha A, ed), pp 603-661. New York: Plenum.

Hoffman GE, Lee W-S, Attardi B, Yann V, Fitzsimmons MD (1990) Leutenizing hormone-releasing hormone neurons express c-fos antigen after steroid activation. Endocrinology 126:1736-1741.

Juurlink BHJ, Hertz L (1985) Plasticity of astrocytes in primary cultures: an experimental tool and a reason for methodological caution. Dev Neurosci 7:263-277.

Kanai Y, Hediger MA (1992) Primary structure and functional characterization of a high-affinity glutamate transporter. Nature 360:467-471.

Kirschner MA, Copeland NG, Gilbert DJ, Jenkins NA, Amara SG (1994) Mouse excitatory amino acid transporter EAAT2: isolation, characterization, and proximity to neuroexcitability loci on mouse chromosome 2 . Genomics 24:218-224.

Kondo K, Hashimoto H, Kitanaka J, Sawada M, Suzumura A, Marunouchi T, Baba A (1995) Expression of glutamate transporters in cultured glial cells. Neurosci Lett 188:140-142.

Lehre KP, Levy LM, Ottersen OP, Storm-Mathisen J, Danbolt NC (1995) Differential expression of two glial glutamate transporters in the rat brain: quantitative and immunocytochemical observations. J Neurosci 15:1835-1853.

Levy LM, Lehre KP, Walaas SI, Storm-Mathison J, Danbolt NC (1995) Down-regulation of glial glutamate transporters after glutamatergic denervation in the rat brain. Eur J Neurosci 7:2036-2041.

Lowry OH, Rosebrough NH, Farr AL, Randall RJ (1951) Protein measurement with the Folin phenol reagent. J Biol Chem 193:265-275.

Maniatis T, Fritsch EF, Sambrook J (1992) Molecular cloning: a laboratory manual. Cold Spring Harbor, NY: Cold Spring Harbor Laboratory.

McLennan H (1976) The autoradiographic localization of L- $\left[{ }^{3} \mathrm{H}\right]$ glutamate in rat brain tissue. Brain Res 115:139-144.

Nichols DG, Attwell D (1990) The release and uptake of excitatory amino acids. Trends Pharmacol Sci 11:462-468.

Nicholson B, McGivan JD (1996) Induction of high affinity glutamate transport activity by amino acid deprivation in renal epithelial cells does not involve an increase in the amount of transporter protein. J Biol Chem 271:12159-12164.

Pines G, Danbolt NC, Bjøräs M, Zhang Y, Bendahan A, Eide L, Koepsell H, Storm-Mathisen J, Seeberg E, Kanner BI (1992) Cloning and expression of a rat brain L-glutamate transporter. Nature 360:464-467.

Rothstein JD, Dykes-Hoberg M, Pardo CA, Bristol LA, Jin L, Kuncl RW, Kanai Y, Hediger M, Wang Y, Schielke JP, Welty DF (1996) Knockout of glutamate transporters reveals a major role for astroglial transport in excitotoxicity and clearance of glutamate. Neuron 16:675-686.

Rothstein JD, Martin L, Levey AI, Dykes-Hoberg M, Jin L, Wu D, Nash N, Kuncl RW (1994) Localization of neuronal and glial glutamate transporters. Neuron 13:713-725.

Rothstein JD, Van Kammen M, Levey AI, Martin LJ, Kuncl RW (1995) Selective loss of glial glutamate transporter GLT-1 in amyotrophic lateral sclerosis. Ann Neurol 38:73-84.

Ruiz M, Ortega A (1995) Characterization of an $\mathrm{Na}^{+}$-dependent glutamate/aspartate transporter from cultured Bergmann glia. NeuroReport 6:2041-2044. 
Schmitt A, Asan E, Puschel B, Jons Th Kugler P (1996) Expression of the glutamate transporter GLT-1 in neural cells of the rat central nervous system: non-radioactive in situ hybridization and comparative immunocytochemistry. Neuroscience 71:989-1004.

Sensenbrenner M, Labourdette G, Delaunoy JP, Pettmann B, Devilliers G, Moonen G, Bock E (1980) Morphological and biochemical differentiation of glial cells in primary culture. In: Tissue culture in neurobiology (Giacobini E, ed), pp 385-395. New York: Raven.

Stein BS, Miller JW, Farrell K, Longuemare MC, Rothstein JD, Swanson RA (1996) Glutamate transporter expression in rat cortical cultures. Soc Neurosci Abstr 618:20.

Storck T, Schulte S, Hoffman K, Stoffel W (1992) Structure, expression, and functional analysis of a $\mathrm{Na}^{+}$-dependent glutamate/aspartate transporter from rat brain. Proc Natl Acad Sci USA 89:10955-10959.

Sutherland ML, Delaney TA, Noebels JL (1996) Glutamate transporter
mRNA expression in proliferative zones of the developing and adult murine CNS. J Neurosci 16:2191-2207.

Suzumura A, Marunouchi T, Yamamoto H (1991) Morphological transformation of microglia in vitro. Brain Res 545:301-306.

Swanson RA, Farrell K, Simon RP (1995) Acidosis and hypoxia cause astrocyte ATP depletion and failure of glutamate uptake. J Cereb Blood Flow Metab 15:417-424.

Tanaka K (1994) Pharmacological characterization of a cloned rat glutamate transporter (GluT-1). Mol Brain Res 21:167-170.

Vandenberg RJ, Arriza JL, Amara SG, Kavanaugh MP (1995) Constitutive ion fluxes and substrate binding domains of human glutamate transporters. J Biol Chem 270:17668-17671.

Zerangue N, Arriza JL, Amara SG, Kavanaugh MP (1995) Differential modulation of human glutamate transporter subtypes by arachidonic acid. J Biol Chem 270:6433-6435. 